\title{
Identification of residues in the BST-2 TM domain important for antagonism by HIV-1 Vpu using a gain-of-function approach
}

\author{
Takeshi Yoshida, Sandra Kao and Klaus Strebel* \\ Viral Biochemistry Section, Laboratory of Molecular Microbiology, National Institute of Allergy and Infectious Diseases, National Institutes of Health, Bethesda, MD, USA
}

\section{Edited by:}

Tom C. Hobman, University of British

Columbia, Canada

\section{Reviewed by:}

Keith Fowke, University of Manitoba,

Canada

Carolyn Machamer, Johns Hopkins

University School of Medicine, USA

*Correspondence:

Klaus Strebel, Viral Biochemistry Section, Laboratory of Molecular

Microbiology, National Institute of Allergy and Infectious Diseases,

National Institutes of Health, Building

4, Room 310, 4 Center Drive MSC

0460, Bethesda, MD 20892-0460,

USA.

e-mail:kstrebel@nih.gov
The HIV-1 Vpu protein enhances the release of viral particles from the cell-surface in a cell-type specific manner. In the absence of $\mathrm{Vpu}$, nascent virions remain tethered to the cell-surface in restricted cell-types. Recently, the human host factor BST-2/CD317/tetherin was found to be responsible for the inhibition of virus release. It was also reported that HIV-1 Vpu can target human BST-2 but is unable to interfere with the function of murine or simian BST-2. We performed a gain-of-function study to determine which of the differences between human and rhesus BST-2 account for the differential sensitivity to Vpu. We transferred human BST-2 sequences into rhesus BST-2 and assessed the resulting chimeras for inhibition of HIV-1 virus release and sensitivity to Vpu. We found that rhesus BST-2 carrying the transmembrane (TM) domain of human BST-2 is susceptible to HIV-1 Vpu. Finally, a single-amino-acid change in the rhesus BST-2TM domain was sufficient to confer Vpu sensitivity.

Keywords: BST-2, tetherin, Vpu, restriction factor, HIV-1

\section{INTRODUCTION}

Efficient virus release from HIV-infected cells is regulated by its Vpu gene product (Strebel et al., 1988; Terwilliger et al., 1989). However, the dependence on Vpu for efficient virus release is celltype dependent (Sakai et al., 1995), leading investigators to predict the presence of a host restriction factor in Vpu-dependent cell-types (Varthakavi et al., 2003). Interestingly, IFN-treatment of Vpu-independent cell-types created a Vpu-dependent phenotype and inhibited not only the release of HIV-1 and related retroviruses but also affected secretion of unrelated viruses such as porcine endogenous retrovirus (PERV), Ebola, Lassa, Marburg, endogenous betaretrovirus of sheep (enJSRV), and KSHV (Neil et al., 2007; Jouvenet et al., 2009; Kaletsky et al., 2009; Sakuma et al., 2009b; Arnaud et al., 2010; Mattiuzzo et al., 2010). These observations suggested that the $\mathrm{Vpu}$-sensitive restriction factor was not specific to HIV but belonged to a family of interferoninducible genes with general antiviral properties. In the course of a quantitative membrane proteomics study, Vpu was found to reduce cellular expression of BST-2 in HeLa cells (Bartee et al., 2006). Subsequent reports identified BST-2 as the IFN-inducible, Vpusensitive factor responsible for the restriction of HIV-1 virus release (Neil et al., 2008; Van Damme et al., 2008). Indeed, BST-2 expression was cell-type dependent. BST-2 was constitutively expressed in Vpu-dependent cell-types such as HeLa, Jurkat, or CD4+ T cells but was undetectable in cell-types such as 293T or HT1080 cells and thus corresponded to cell-types known to depend on Vpu for efficient virus release (Neil et al., 2008; Van Damme et al., 2008). Importantly, BST-2 expression was induced by interferon treatment in 293T and HT1080 cells (Neil et al., 2007, 2008) and ectopic expression of BST-2 in 293T or HT1080 cells rendered these cells Vpu-dependent (Neil et al., 2008; Van Damme et al., 2008). Finally,
siRNA silencing of BST-2 rendered virus release from HeLa cells Vpu-independent (Neil et al., 2008; Van Damme et al., 2008; Rong et al., 2009). Taken together these data provided strong evidence that BST-2 was indeed the host factor whose inhibitory effect on virus release was counteracted by Vpu.

BST-2 is a $30-$ to $36-\mathrm{kDa}$ type II integral membrane protein, consisting of 180 amino acids (Ishikawa et al., 1995). The protein has an $\mathrm{N}$-terminal transmembrane (TM) domain and is presumed to contain a C-terminal glycosyl-phosphatidylinositol (GPI) anchor (Kupzig et al., 2003; Figure 1A). BST-2 protein associates with lipid rafts at the cell-surface and on internal membranes, presumably the trans-Golgi network (TGN; Kupzig et al., 2003; Dube et al., 2009; Masuyama et al., 2009). X-ray crystallography of recombinant BST-2 demonstrated that residues 47-148 of the protein's ectodomain can fold into a $90-\AA ̊$ parallel coiled-coil structure (Hinz et al., 2010). In addition, small-angle $X$-ray scattering analyses predicted that the complete extracellular region of BST- 2 adopts a long bent rodlike structure that separates the TM domain and GPI anchor by approximately $170 \AA$ (Hinz et al., 2010).

Biochemical analyses demonstrated that BST-2 forms stable cysteine-linked dimers (Goto et al., 1994; Ohtomo et al., 1999; Andrew et al., 2009; Perez-Caballero et al., 2009) and is modified by N-linked glycosylation (Ohtomo et al., 1999; Kupzig et al., 2003; Andrew et al., 2009). The formation of cysteine-linked dimers can be catalyzed by any one of three cysteine residues in the BST-2 ectodomain. Interestingly, BST-2 dimerization was not essential for BST-2 cell-surface expression or sensitivity to Vpu but is critical for inhibition of HIV-1 release (Andrew et al., 2009; Perez-Caballero et al., 2009). The functional role of BST-2 glycosylation on the other hand is still debated (Andrew et al., 2009; Perez-Caballero et al., 2009; Sakuma et al., 2009a). 
Vpu and BST-2 are both integral membrane proteins albeit with different membrane topologies. BST-2 has a short N-terminal cytoplasmic domain with the bulk of the protein comprising the C-terminal ectodomain. Vpu, on the other hand, has virtually no ectodomain, and essentially consists of an N-terminal TM domain and a C-terminal cytoplasmic domain. Recent data suggest that the BST-2 TM domain is critical for interference by Vpu (Douglas et al., 2009; Dube et al., 2009; Gupta et al., 2009; McNatt et al., 2009; Mitchell et al., 2009; Perez-Caballero et al., 2009; Rong et al., 2009) consistent with our previous observation of the importance of the Vpu TM domain for the regulation of virus release (Schubert et al., 1996). Indeed, physical interaction of Vpu and BST-2 and the critical importance of the BST-2 TM domain for this interaction was demonstrated in the course of co-immunoprecipitation studies (Douglas et al., 2009; Gupta et al., 2009; Iwabu et al., 2009; Jia et al., 2009; McNatt et al., 2009; Rong et al., 2009; Dube et al., 2010) and bimolecular fluorescence complementation analyses (Kobayashi et al., 2011). Infection of cells by wild type (wt) virus results in the redistribution of BST-2 from the plasma membrane to early endosomes (Neil et al., 2006; Habermann et al., 2010). This involves internalization of BST-2 through clathrin-dependent endocytosis (Rollason et al., 2007; Masuyama et al., 2009; Mitchell et al., 2009). As for Vpu, the protein is predominantly localized to membranes of the Golgi and TGN (Klimkait et al., 1990; Schubert et al., 1996; Varthakavi et al., 2006) and was found to colocalize with BST-2 in endosomes and the TGN (Rollason et al., 2007; Neil et al., 2008; Van Damme et al., 2008; Douglas et al., 2009; Dube et al., 2009). Furthermore, Vpu mutants affected in TGN localization were unable to antagonize BST-2 suggesting that Vpu targets BST-2 in this compartment (Dube et al., 2009). However, Vpu was also identified at the cell-surface (Bour et al., 1999) and a direct effect of Vpu on cell-surface BST-2 cannot be ruled out. In fact, one recent study proposed that Vpu targets BST-2 at the plasma membrane (Iwabu et al., 2009).

The current study aims at further analyzing the regions in BST-2 that define sensitivity to Vpu. Our approach was to transfer sequences from human BST-2 into the Vpu-resistant rhesus BST-2 to check function and Vpu sensitivity of the resulting chimera. Interestingly, mutation of a single residue in rhesus BST-2 (I48T) was sufficient to significantly increase sensitivity to Vpu. These results are consistent with a recent report demonstrating that mutation of T45 in human BST-2 (which is the equivalent of I48 in rhesus BST-2) was sufficient to render human BST-2 significantly less sensitive to Vpu (Gupta et al., 2009). These results suggest that resistance or sensitivity of BST-2 isolates to Vpu can be regulated by relatively subtle changes in BST- 2 .

\section{MATERIALS AND METHODS PLASMIDS}

The full length infectious HIV-1 molecular clone pNL4-3 and the Vpu deletion mutant pNL4-3/Udel have been described (Adachi et al., 1986; Klimkait et al., 1990). For transient expression of Vpu, the codon-optimized vector pcDNA-Vphu (Nguyen et al., 2004) was employed. Plasmid pcDNA-BST-2 is a vector for the expression of human BST-2 under the control of the cytomegalovirus immediate-early promoter (Andrew et al., 2009). Rhesus BST-2 was amplified by RT-PCR from rhesus macaque RNA using the primers 5'-ATAAC TCGAG GTGGA ATTCA TGGCA CCTAT TTTGT ATGAC and 3'-ATATT GGTAC CTCAC AGCAG CAGAG CGCTC AAGCC CAGCA GCAG. The rhesus macaque RNA was isolated from a pool of activated PBMC of eight rhesus macaques. The resulting PCR product was cleaved with XhoI and KpnI and cloned into the XhoI/KpnI sites of pcDNA3.1(-) (Invitrogen Corp., Carlsbad, CA, USA). The nucleotide sequence of cloned cDNAs was verified by sequence analysis.

\section{ANTISERA}

Anti-BST-2 antiserum was elicited in rabbits using a bacterially expressed MS2-BST-2 fusion protein composed of amino acids 1-91 of the MS2 replicase (Strebel et al., 1986) and amino acids 41-162 of BST-2 generating a polyclonal antibody against the extracellular portion of BST-2. The antibody was found to react with human as well as rhesus BST-2. Polyclonal anti-Vpu serum (rabbit), directed against the hydrophilic C-terminal cytoplasmic domain of Vpu expressed in Escherichia coli (Maldarelli et al., 1993) was used for detection of Vpu. Serum from an HIV-positive patient was used to detect HIV-1-specific capsid (CA) and Pr55gag precursor proteins. Tubulin was identified using a monoclonal antibody to $\alpha$-tubulin (Sigma-Aldrich, Inc., St. Louis, MO, USA).

\section{TISSUE CULTURE AND TRANSFECTIONS}

293T cells were propagated in Dulbecco's modified Eagles medium (DMEM) containing 10\% fetal bovine serum (FBS). For transfection, cells were grown in $25 \mathrm{~cm}^{2}$ flasks to about $80 \%$ confluency. Cells were transfected using TransIT ${ }^{\circledast}$ LT-1 (Mirus, Madison, WI, USA) following the manufacturer's recommendations. A total of $5.2 \mu \mathrm{g}$ of plasmid DNA per $25 \mathrm{~cm}^{2}$ flask was used. Total amounts of transfected DNA was kept constant in all samples of any given experiment by adding empty vector DNA as appropriate. Cells were harvested $24 \mathrm{~h}$ post-transfection.

\section{METABOLIC LABELING AND IMMUNOPRECIPITATIONS}

Cells were transfected as described in the text with constant amounts of proviral vectors and increasing amounts of BST-2. Twenty-four hours later, cells were washed with PBS, scraped, and resuspended in $3 \mathrm{ml}$ labeling media lacking methionine (Millipore Corp., Billerica, MA, USA). Cells were then incubated for $10 \mathrm{~min}$ at $37^{\circ} \mathrm{C}$ to deplete the endogenous methionine pool. Cells were then suspended in $400 \mu \mathrm{l}$ of labeling medium together with $150 \mu \mathrm{Ci}$ of Express ${ }^{35} \mathrm{~S}^{35} \mathrm{~S}$ protein labeling mix (Perkin Elmer, Shelton, CT, USA). Cells were labeled for $90 \mathrm{~min}$ at $37^{\circ} \mathrm{C}$. Cells and virus-containing supernatants were then separated by centrifugation and processed separately for immunoprecipitation as follows: Cells were lysed with $150 \mu \mathrm{l}$ of Triton lysis buffer (50 mM Tris $\mathrm{pH} 7.5,150 \mathrm{mM} \mathrm{NaCl}, 0.5 \%$ Triton$\mathrm{X} 100)$ and incubated on ice for $5 \mathrm{~min}$. After lysis, the cells were pelleted at $13,000 \times \mathrm{g}$ for $2 \mathrm{~min}$ to remove insoluble material. The supernatants were used for immunoprecipitation. Virus-containing supernatants were treated with $150 \mu$ l of Triton lysis buffer to disrupt viral membranes. Cell and virus lysates were adjusted to $1.1 \mathrm{ml}$ total volume with PBS containing BSA (final concentration of BSA: $0.1 \%$ ) and incubated on a rotating wheel for $1 \mathrm{~h}$ at $4^{\circ} \mathrm{C}$ with protein A-Sepharose coupled with an HIV-positive patient serum. Beads were washed twice with wash buffer (50 mM Tris pH 7.4, $300 \mathrm{mM}$ $\mathrm{NaCl}, 0.1 \%$ Triton $\mathrm{X}-100)$. Bound proteins were eluted by heating 
in sample buffer for $10 \mathrm{~min}$ at $95^{\circ} \mathrm{C}$, separated by SDS-PAGE, and visualized by fluorography. Virus release was quantified by phospho-image analysis using a Fujifilm FLA7000 system.

\section{RESULTS}

\section{CLONING OF RHESUS BST-2}

Pooled RNA from eight rhesus macaques was used for RT-PCR amplification of BST-2 and the resulting cDNA was cloned in untagged form into pcDNA3.1(-) as described in Section
"Materials and Methods." Four independent clones were sequenced and aligned against the GenBank entry of Macaca mulatta (GenBank NM_001161666). We also included in our alignment the sequences of three recently described rhesus macaque isolates (McNatt et al., 2009; Figure 1A). Interestingly, rhesus BST-2 exhibited sequence polymorphism at five positions (residues 9, 14, 29, 111, and 159). Two polymorphic sites each were located in the protein's cytoplasmic and ecto-domains; one polymorphic site mapped to the TM domain (highlighted in black

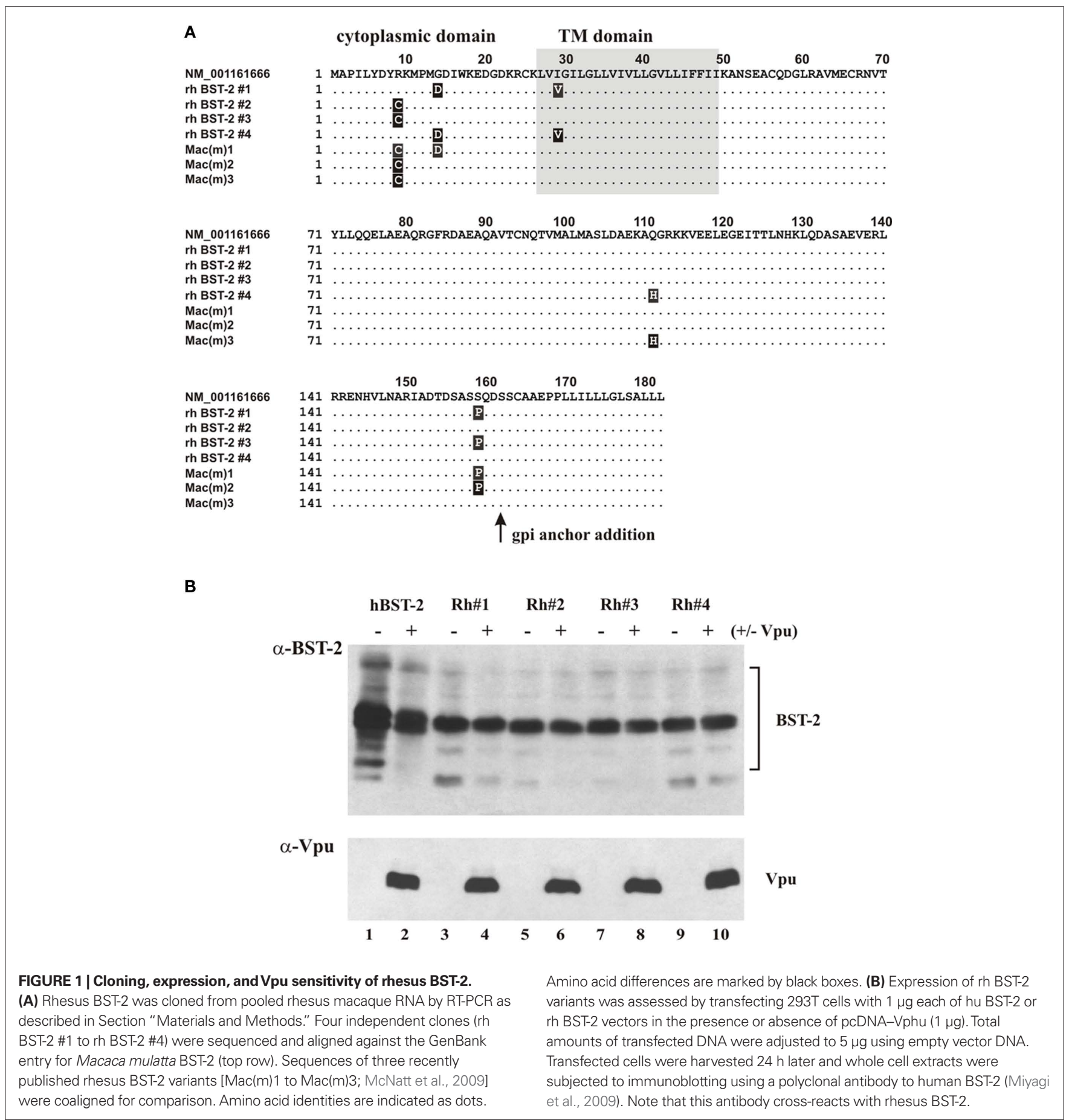


in Figure 1A). In fact, all four rhesus BST-2 clones were different from each other and from the GenBank entry, and only one of our clones (rh BST-2 \#3) was identical to one of three rhesus variants described previously [Figure 1A; $\operatorname{Mac}(\mathrm{m}) 2$ ]. We tested expression and sensitivity to $\mathrm{Vpu}$-induced degradation of all four rhesus BST-2 variants in transfected $293 \mathrm{~T}$ cells and found no striking differences (Figure 1B). As reported previously, transient transfection of cells with BST-2 vectors results in the production of a dominant protein species of $\sim 29 \mathrm{kDa}$ representing immature BST-2 carrying high-mannose carbohydrate modifications (Andrew et al., 2009). In addition, a diffuse pattern of proteins from 30 to $40 \mathrm{kDa}$ is evident in Figure 1B, representing mature forms of BST-2 containing complex carbohydrate modifications (Andrew et al., 2009). Consistent with previous observations, human BST-2 levels were partially reduced in the presence of Vpu (Figure 1B, compare lanes 1 and 2) while rhesus BST-2 levels remained essentially unaltered in the presence or absence of $\mathrm{Vpu}$ (Figure 1B, lanes 3-10). We empirically chose rhesus BST-2 clone \#4 for all subsequent functional studies.

\section{HIV-1 Vpu COUNTERACTS HUMAN BUT NOT RHESUS BST-2}

To further understand the susceptibility of BST-2 to HIV-1 Vpu we compared the ability of human BST-2 and rhesus BST-2 to inhibit release of wt and Vpu-deficient (Udel) HIV-1. The human kidney cell line 293T, which does not express detectable levels of endogenous BST-2 and does not inhibit release of Vpu-deficient HIV-1 (Neil et al., 2008; Van Damme et al., 2008; Miyagi et al., 2009) was used to assess the effects of transiently expressed human or rhesus BST-2 on the release of wt NL4-3 and Vpu-deficient NL4-3/Udel viruses. We started out by comparing the dose-dependent effects of untagged human and rhesus BST-2 on virus release (Figure 2A). For that purpose $293 \mathrm{~T}$ cells were transfected with wt pNL4-3 or pNL4-3/Udel ( $5 \mu \mathrm{g}$ each) in the absence or presence of increasing amounts of human or rhesus BST-2 $(0-0.2 \mu \mathrm{g}$ plasmid DNA as indicated in Figure 2B). Twenty-four hour post-transfection, cells were metabolically labeled for $90 \mathrm{~min}$ and cell and viral extracts were immunoprecipitated using an HIV-positive patient serum. Proteins were visualized by fluorography (Figure 2A) and quantified by phospho-image analysis (Figure 2B). The ratio of virus associated Gag protein relative to the total intra- and extracellular Gag was determined and plotted as a function of BST-2 DNA concentration (Figure 2B). As expected, human and rhesus BST-2 inhibited release of NL4-3 Udel virus in a dose-dependent manner (Figure 2B, open circles), In addition, we found that rhesus BST-2 inhibited the release of wt NL4-3 as efficiently as Vpu-deficient virus (Figure 2B, bottom; solid circles). In contrast, Vpu was able to counteract the inhibitory effect of human BST-2 (Figure 2B, top, solid circles); however, human BST-2 also inhibited the release of wt NL4-3 at higher levels of expression consistent with previous reports (Van Damme et al., 2008). Relative expression of human and rhesus BST-2 was determined by immunoblotting (Figure 2C). As expected, transfection of increasing amounts of plasmid DNA resulted in a dose-dependent increase in BST-2 expression. These results indicate that release of HIV-1 virions from $293 \mathrm{~T}$ cells is inhibited by both human and rhesus BST-2; however, only human BST- 2 could be counteracted by HIV-1 Vpu.

\section{RHESUS BST-2 CARRYING THE TM DOMAIN OF HUMAN BST-2 IS SUSCEPTIBLE TO HIV-1 Vpu}

Several previous studies concluded that the BST-2 TM domain is critical for sensitivity to Vpu (Goffinet et al., 2009; Gupta et al., 2009; Iwabu et al., 2009; McNatt et al., 2009; Rong et al., 2009; Dube et al., 2010). However, in two of these studies (Goffinet et al., 2009; Dube et al., 2010) transfer of the human TM domain to African green monkey (agm), murine, or rat BST-2 did not restore sensitivity to Vpu while in a third study (McNatt et al., 2009) transfer of the human BST-2 TM domain into agm and rhesus BST-2 resulted in gain of Vpu sensitivity. To further characterize the determinants of human BST-2 required for susceptibility to $\mathrm{Vpu}$, we used a similar gain-of-function approach by transferring portions of human BST-2 into the Vpu-resistant rhesus BST-2 variant \#4. For that purpose we generated a series of rhesus BST-2 chimeras as illustrated in Figure 3A. The design of the chimera was based on regions of sequence diversity between human and rhesus BST-2 (Figure 3B). Expression of chimeric BST-2 proteins was determined by immunoblotting (Figure 3C). Each chimera was analyzed for gain of Vpu sensitivity. Virus release in the presence or absence of $\mathrm{Vpu}$ was determined by metabolic labeling as described for Figure 2A. The results are shown in Figure 4. We found that only chimera 4 and chimera 7 containing parts or all of the human BST-2 TM domain gained significant sensitivity to Vpu. All other chimeras inhibited virus release irrespective of the presence or absence of $\mathrm{Vpu}$. The fact that all chimera inhibited virus release indicates that the synthesis and trafficking of these proteins was comparable to the parental wt proteins. The finding that transfer of residues 30-45 of human BST-2 into rhesus BST-2 (chimera 4) is sufficient to confer sensitivity to Vpu indicates that sequences critical to Vpu sensitivity are located in the C-terminal part of the BST-2 TM domain.

\section{A SINGLE-AMINO-ACID CHANGE RENDERS RHESUS BST-2 PARTIALLY SUSCEPTIBLE TO HIV-1 Vpu}

The region of human BST-2 transferred into chimera 4 differs from rhesus BST-2 in six amino acid positions (Figure 5A). To analyze the importance of each of these residues to Vpu sensitivity, we generated additional chimeras containing single-amino-acid changes relative to the parental rhesus BST-2 variant. Each of the six amino acid positions was altered individually resulting in chimeras G33V,V36I, L39I, L43P, F46I, and I48T, respectively (Figure 5A). Expression of the variants was confirmed by immunoblotting (Figure 5B). Finally, we assessed the susceptibility of these mutants by metabolic labeling as shown for Figure 2 (Figure 6). Interestingly, mutation of I48T induced partial sensitivity of rhesus BST-2 to Vpu, especially at low levels of BST-2. In contrast, all other mutants remained fully Vpu-resistant. Thus, mutation of the rhesus BST-2 TM domain at position 48 from isoleucine to threonine was sufficient to render rhesus BST-2 partially susceptible to Vpu.

\section{DISCUSSION}

CD4 degradation and regulation of virus release, which are the two best-studied functions of $\mathrm{Vpu}$, involve distinct structural domains of Vpu (Schubert et al., 1996). The ability to degrade CD4 is critically dependent on Vpu's cytoplasmic domain, and in particular a 


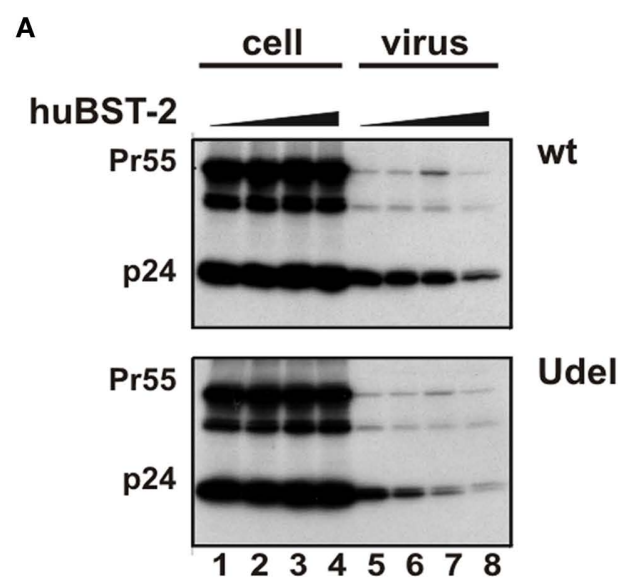

B
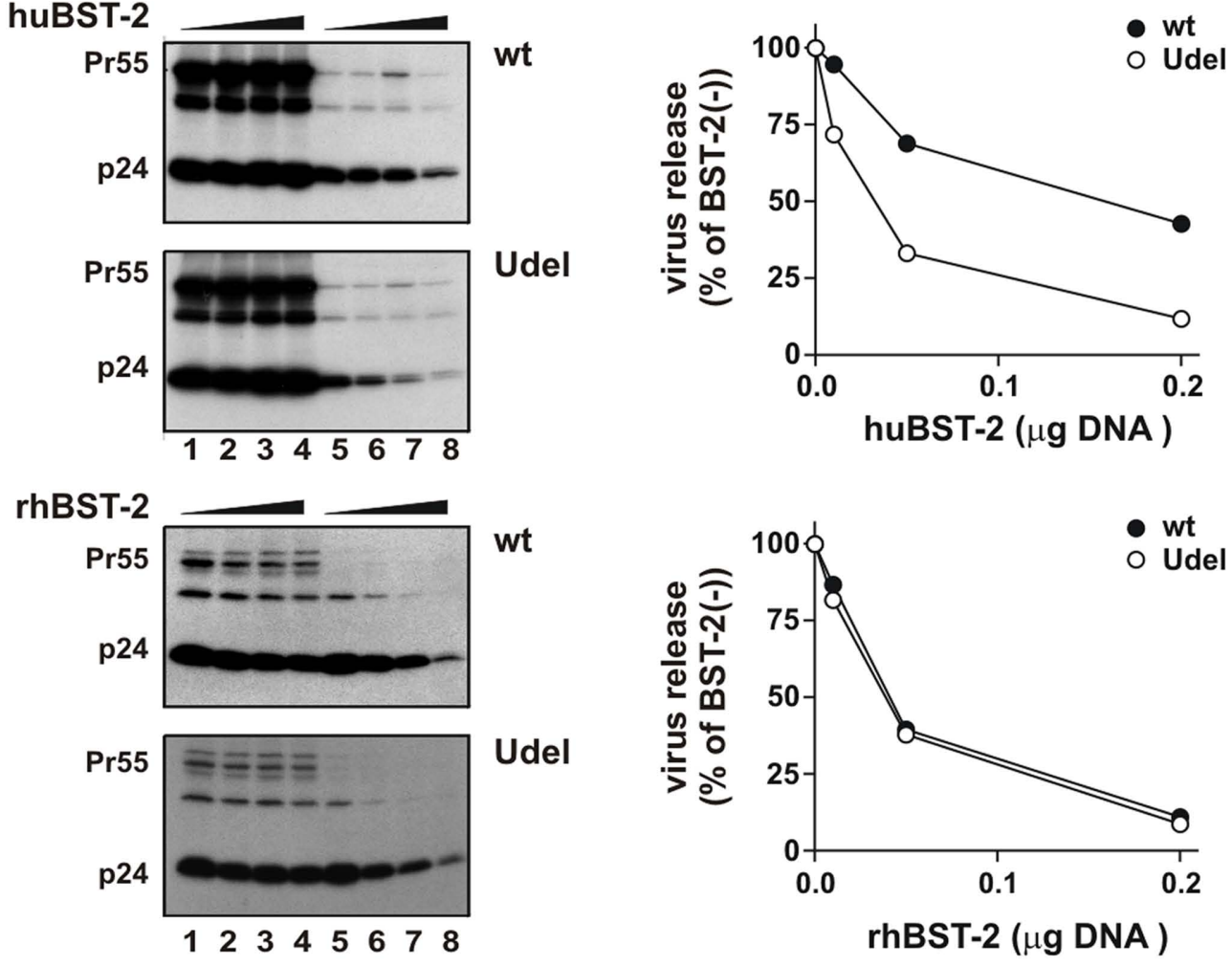

C

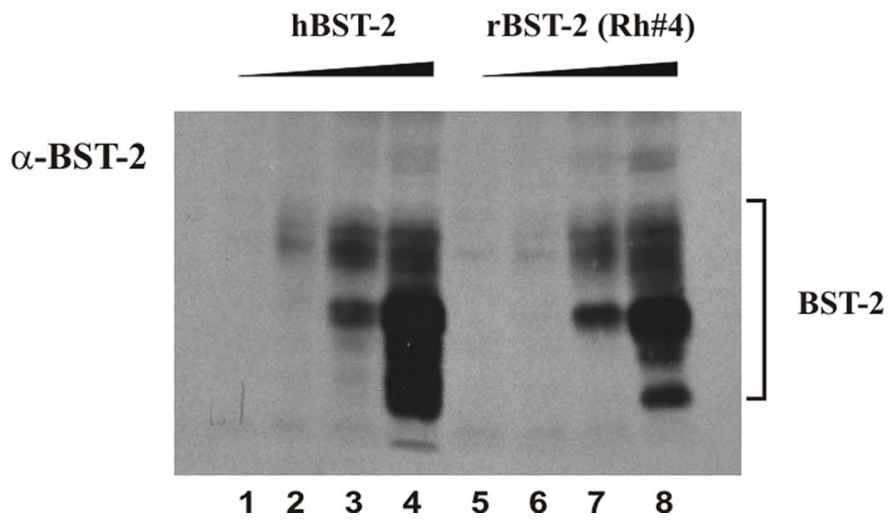

FIGURE 2 | HIV-1 Vpu counteracts human but not rhesus BST-2. (A) 293T cells were transfected with $5 \mu \mathrm{g}$ of either pNL4-3 (wt) or pNL4-3/Udel (Udel) in the absence of BST-2 (lanes 1 and 5) or in the presence of $0.01 \mu \mathrm{g}$ (lanes 2 and 6 ), $0.05 \mu \mathrm{g}$ (lanes 3 and 7), or $0.2 \mu \mathrm{g}$ (lanes 4 and 8) human (top panel) or rhesus (bottom panel) BST-2. Metabolic labeling was carried out as described in the text and cell lysates and cell-free supernatants were subjected to immunoprecipitation using an HIV-positive pooled human serum. Samples were separated by

SDS-PAGE and proteins were visualized by fluorography. (B) Gag-specific cellular and viral proteins (Pr55 and p24) were quantified by phospho-image analysis. Solid circles represent samples expressing NL4-3; open circles represent NL4-3/Udel.
The amount of p24 released in the absence of BST-2 relative to the total intra- and extracellular Gag protein was defined as $100 \%$. Virus release in the presence of increasing amounts of BST-2 was calculated accordingly and the results were plotted as a function of transfected BST-2 DNA. (C) Expression of BST-2 was analyzed by immunoblotting. 293T cells were transfected with 0 (lanes 1 and 5), 0.01 (lanes 2 and 6), 0.05 (lanes 3 and 7), or $0.2 \mu$ (lanes 4 and 8) of human BST-2 or rhesus BST-2 as in (A). Total amounts of transfected DNA were adjusted to $5 \mu \mathrm{g}$ using empty vector DNA as appropriate. Whole cell lysates were prepared $24 \mathrm{~h}$ after transfection and subjected to immunoblot analysis using a BST-2 specific antibody as described in Figure 1B. 


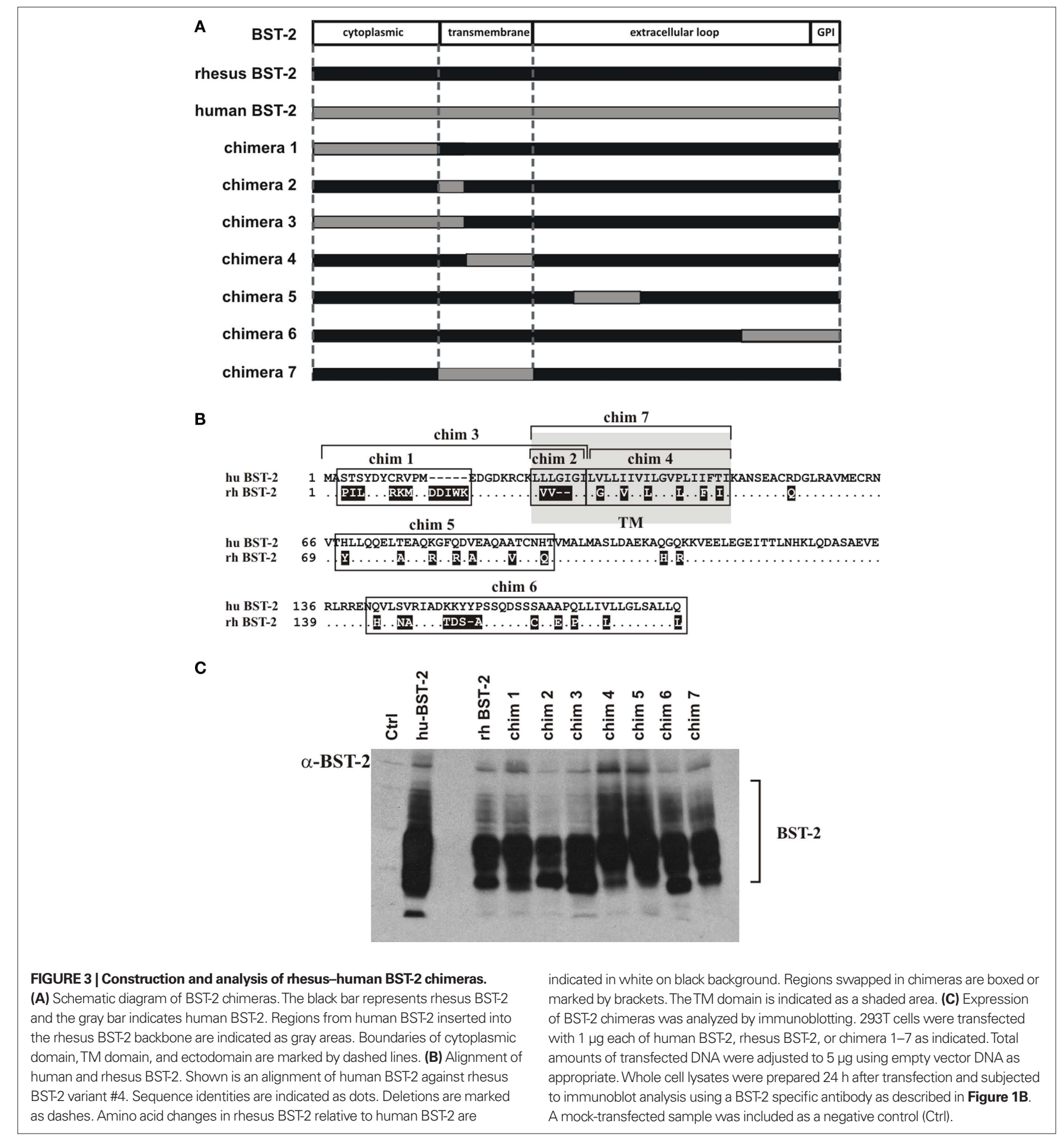

di-phosphoserine motif, which is necessary for the assembly of an ubiquitin ligase complex that ultimately marks CD4 for degradation by the cellular proteasome machinery (reviewed in Strebel, 2007; Andrew and Strebel, 2010). Although critical elements involved in the binding of Vpu to CD4 have been mapped to the Vpu and CD4 cytoplasmic domains (Raja et al., 1994; Willey et al., 1994; Yao et al., 1995; Tiganos et al., 1997) some reports have noted an additional involvement of the Vpu and CD4 TM domains (Buonocore et al., 1994; Raja et al., 1994; Magadan et al., 2010). However, the contribution of the TM domains for CD4-Vpu interaction appears to be relatively non-specific since the TM domains of both proteins can be replaced by heterologous TM domains without loss of CD4 degradation (Willey et al., 1994; Bour et al., 1995; Hout et al., 2005, 2006). Also, scrambling the Vpu TM domain had virtually no effect 

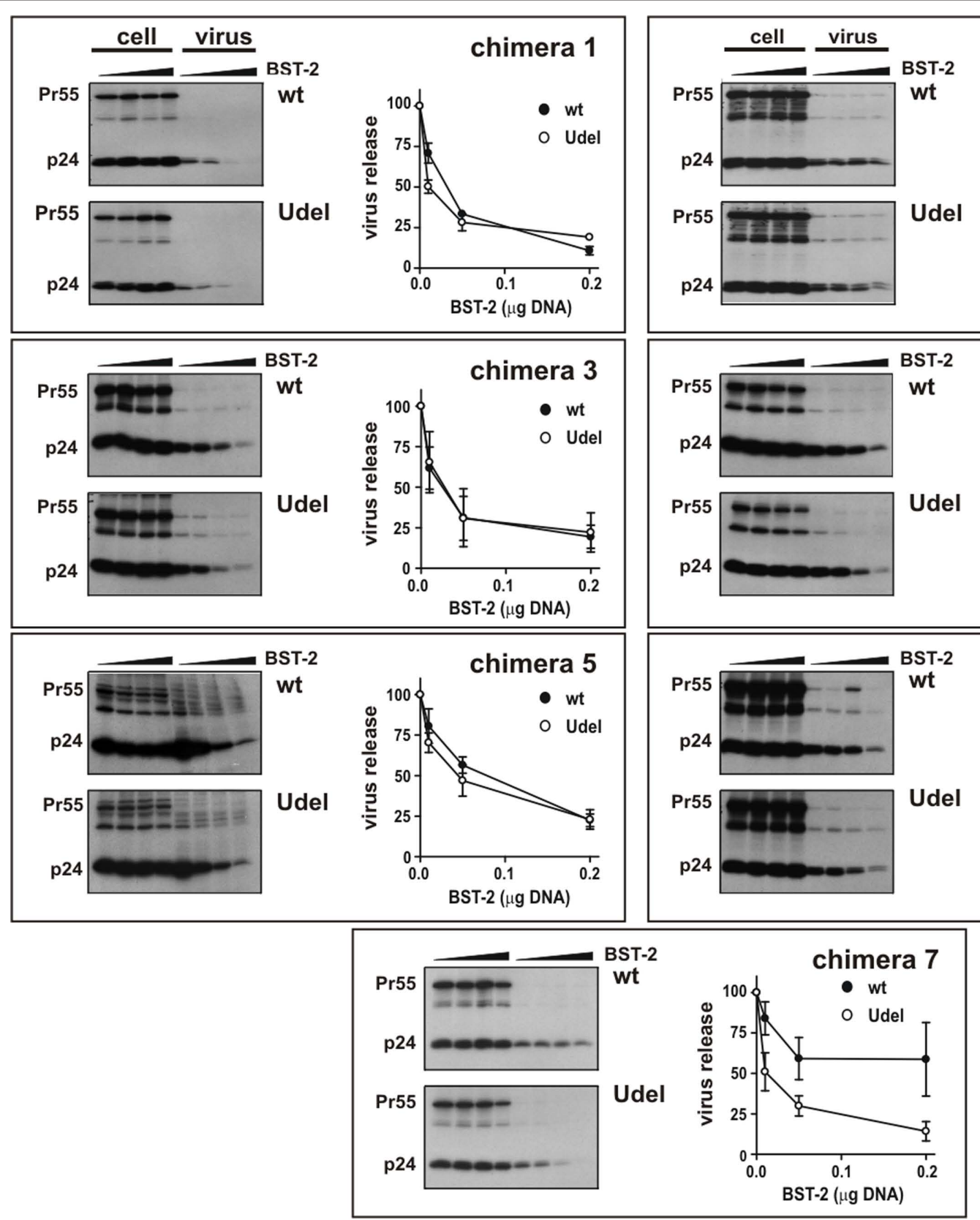

FIGURE 4 | Analysis of rhesus BST-2 carrying the TM domain of human BST-2 for susceptibility to HIV-1 Vpu. 293T cells were transfected with $5 \mathrm{\mu g}$ of either pNL4-3 (wt) or pNL4-3/Udel (Udel) in the absence of BST-2 or in the presence of $0.01,0.05$, or $0.2 \mu \mathrm{g}$ BST-2 chimeric constructs as described for
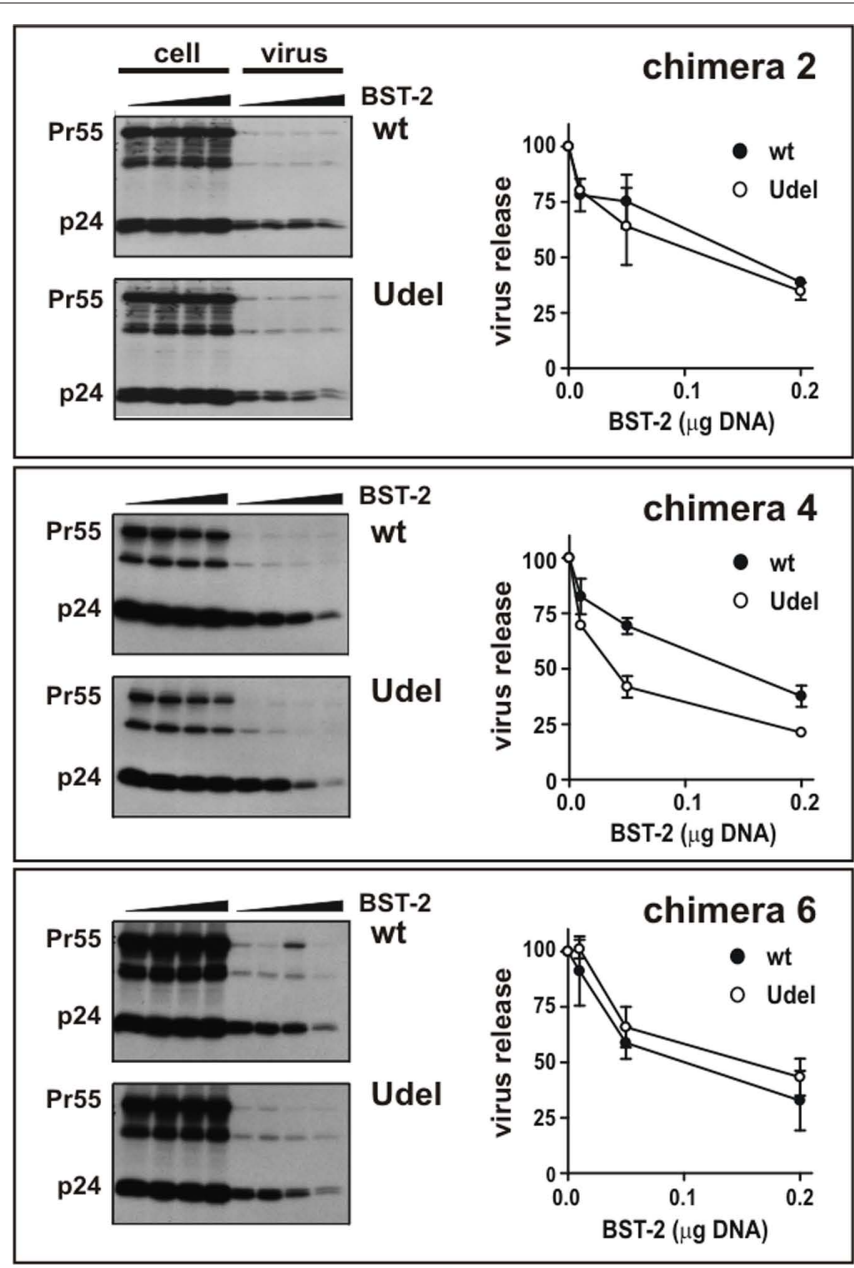

Figure 2A. Metabolic labeling analysis was carried out as described for Figure 2A. Representative fluorographs are shown. Quantitation of virus release is shown on the right of each panel and was performed as described in the legend to Figure 2B. Error bars reflect SEM from two independent experiments. on the ability of Vpu to degrade CD4 (Schubert et al., 1996) suggesting that the primary sequence of the Vpu TM domain is not critical for this function.

On the other hand, the structural integrity of the Vpu TM domain appears to be critical for the enhancement of virus release (Schubert et al., 1996; Paul et al., 1998) and for the interference of Vpu with BST-2 function. Because of the importance of the Vpu TM domain for regulating virus release, it was not particularly surprising that the TM domain of BST-2 was equally important for inhibition by Vpu. Unlike the Vpu-CD4 interaction, however, the sequence of the BST-2 domain is critical for functional interaction with $\mathrm{Vpu}$. The data presented here supports two previous studies showing that transfer of the TM domain of human BST-2 to normally Vpu-insensitive non-human BST-2 variants confers partial or full Vpu sensitivity (McNatt et al., 2009; Rong et al., 2009). It remains unclear why two other studies did not observe a gain of Vpu sensitivity following transfer of the human BST-2 TM domain into agm or rodent BST-2 (Goffinet et al., 2009; Dube 
A

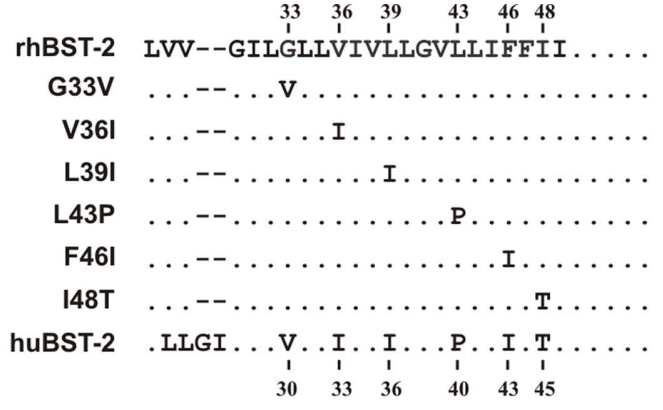

B

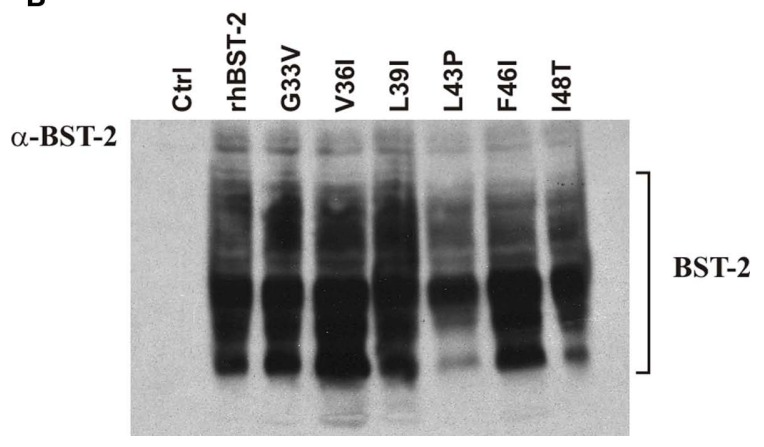

FIGURE 5 | Construction of BST-2 point mutants. (A) Sequence alignment of BST-2 TM domain region encompassed by chimera 4 . Chimera 4 , which is Vpu-sensitive, contains six amino acid differences with respect to rhesus BST-2. Each of the six positions was changed individually to the corresponding human sequence by PCR-based site-directed mutagenesis. Dots represent sequence identities. Amino acid positions at the top refer to rhesus BST-2. Numbers listed at the bottom refer to the corresponding human BST-2 amino acid positions. (B) Expression of BST-2 point mutants was verified by immunoblotting as described for Figure $\mathbf{3 C}$

et al., 2010). However, it is interesting to note that the latter two studies employed BST-2 constructs carrying an N-terminal HA tag while the partially Vpu-sensitive construct used by Rong et al. (2009) carried an N-terminal Flag tag. The fully Vpu-sensitive construct described by McNatt et al. (2009) carried an internal HA tag while our own fully sensitive construct was untagged. It seems therefore possible that differences in the Vpu sensitivity of BST-2 chimeras carrying the human BST-2 TM domain are attributable to the presence of epitope tags in different locations of the protein.

Analysis of the TM domains of human and rhesus BST-2 revealed a number of differences including a deletion of two amino acids near the $\mathrm{N}$-terminus of the rhesus BST-2 TM domain as well as six single-amino-acid differences in the C-terminal half of the TM domain (Figure 5A). The importance of these differences in the TM domains of human and rhesus BST-2 for Vpu sensitivity has been addressed in several previous studies (Gupta et al., 2009; McNatt et al., 2009; Rong et al., 2009; Dube et al., 2010). However, all of these studies conducted loss-offunction analyses, meaning that mutations were introduced into the Vpu-sensitive human BST-2 and the resulting chimeras were tested for loss of Vpu sensitivity. In contrast, our own strategy was a gain-of-function approach which involved the introduction of human BST-2 sequences into the backbone of Vpu-resistant rhesus BST-2 and measuring resulting chimeras for gain of Vpu sensitivity. In addition, our experiments were done using untagged protein species. Previous studies agree that deletion of a GI amino acid motif present in human BST-2 but absent in non-human BST-2 variants, combined with mutation of T45I, resulted in complete loss of Vpu sensitivity. Mutation of T45I alone was found to induce partial loss of Vpu sensitivity (Gupta et al., 2009; McNatt et al., 2009; Rong et al., 2009). The importance of a di-leucine motif near C-terminal end of the human BST-2 TM domain is unclear. Deletion of the di-leucine motif was found to abolish sensitivity to $\mathrm{Vpu}$ (Rong et al., 2009) while mutation - rather than deletion - of the same motif had only a partial effect on Vpu sensitivity (McNatt et al., 2009). Our own results demonstrate that transfer of the $\mathrm{N}$-terminal segment of the human BST-2 TM domain containing the di-leucine motif as well as the GI motif did not confer Vpu sensitivity to the resulting chimera (Figure 4, chimera 2), thus suggesting that the di-leucine and GI elements may be necessary but are not sufficient to establish Vpu sensitivity. With respect to individual point mutations (Figure 6), our gain-of-function data agree with previous loss-of-function analyses in that most changes of individual amino acids had little or no impact on Vpu sensitivity (Gupta et al., 2009; McNatt et al., 2009; Rong et al., 2009). Our results disagree with previous studies in that mutation of G33V (corresponding to V30G in human BST-2 Gupta et al., 2009; McNatt et al., 2009; Rong et al., 2009) did not confer resistance to $\mathrm{Vpu}$ in our analysis (Figure 6) while mutation of that residue in human BST-2 resulted in a partial loss of Vpu sensitivity. Finally, mutation of I48T in rhesus BST-2 conferred partial Vpu sensitivity in our gain-of-function approach, consistent with the partial loss of Vpu sensitivity of the corresponding I45T mutant in human BST-2 reported previously (Gupta et al., 2009; McNatt et al., 2009; Rong et al., 2009).

Taken together our data demonstrate that transfer of individual residues (i.e., I48T in Figure 6) or parts of the human BST-2 TM domain (i.e., chimera 4 in Figure 4) can confer partial Vpu sensitivity to rhesus BST-2. Thus, the BST-2 TM domain contains the determinants responsible for the species-specific sensitivity to Vpu. How the interaction of Vpu and BST-2 leads to the functional inactivation of BST-2 remains to be investigated. Co-immunoprecipitation and bimolecular fluorescence complementation analyses suggest a direct physical interaction of Vpu and BST-2 (Rong et al., 2009; Dube et al., 2010; Kobayashi et al., 2011). However, binding of Vpu to BST-2 may not be sufficient to neutralize BST-2 and to ensure efficient virus release since at least in one case, transfer of the human TM domain conferred Vpu interaction but did not bestow Vpu sensitivity to agm BST-2 (Dube et al., 2010). It was previously shown that the physical interaction of CD4 and HIV-1 Env in the endoplasmic reticulum can prevent the trafficking of CD4 and HIV-1 Env to the cell-surface (Crise et al., 1990; Jabbar and Nayak, 1990; Bour et al., 1991). Future studies will have to address the possibility that the physical association of Vpu and BST-2 similarly imposes a trafficking defect leading to the depletion of BST-2 from the cell-surface. 


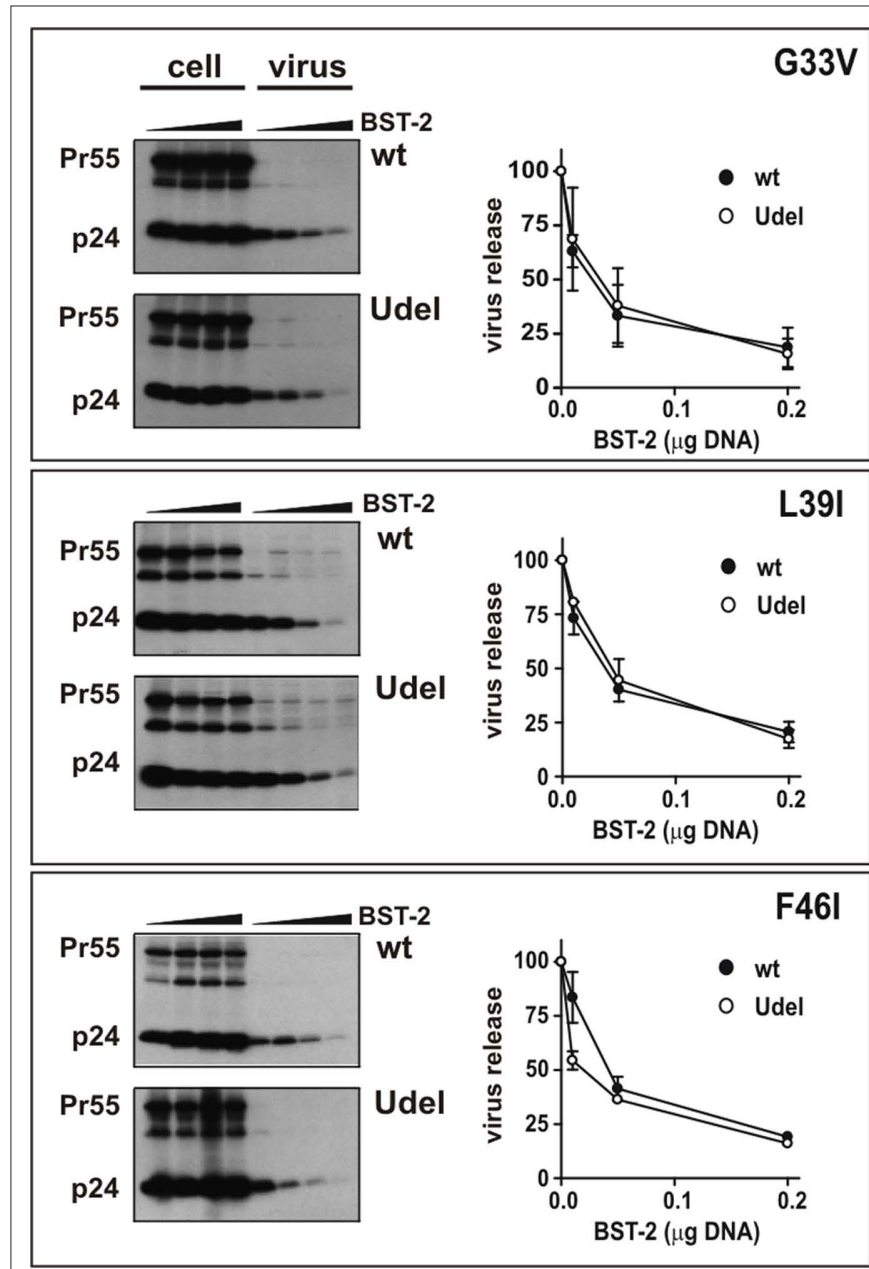

FIGURE 6 |A single-amino-acid change renders rhesus BST-2 partially susceptible to HIV-1 Vpu. Metabolic labeling of viral proteins followed by immunoprecipitation of cell lysates and viral supernatants in the presence of BST-2 point mutants was performed as described for Figure 2A.
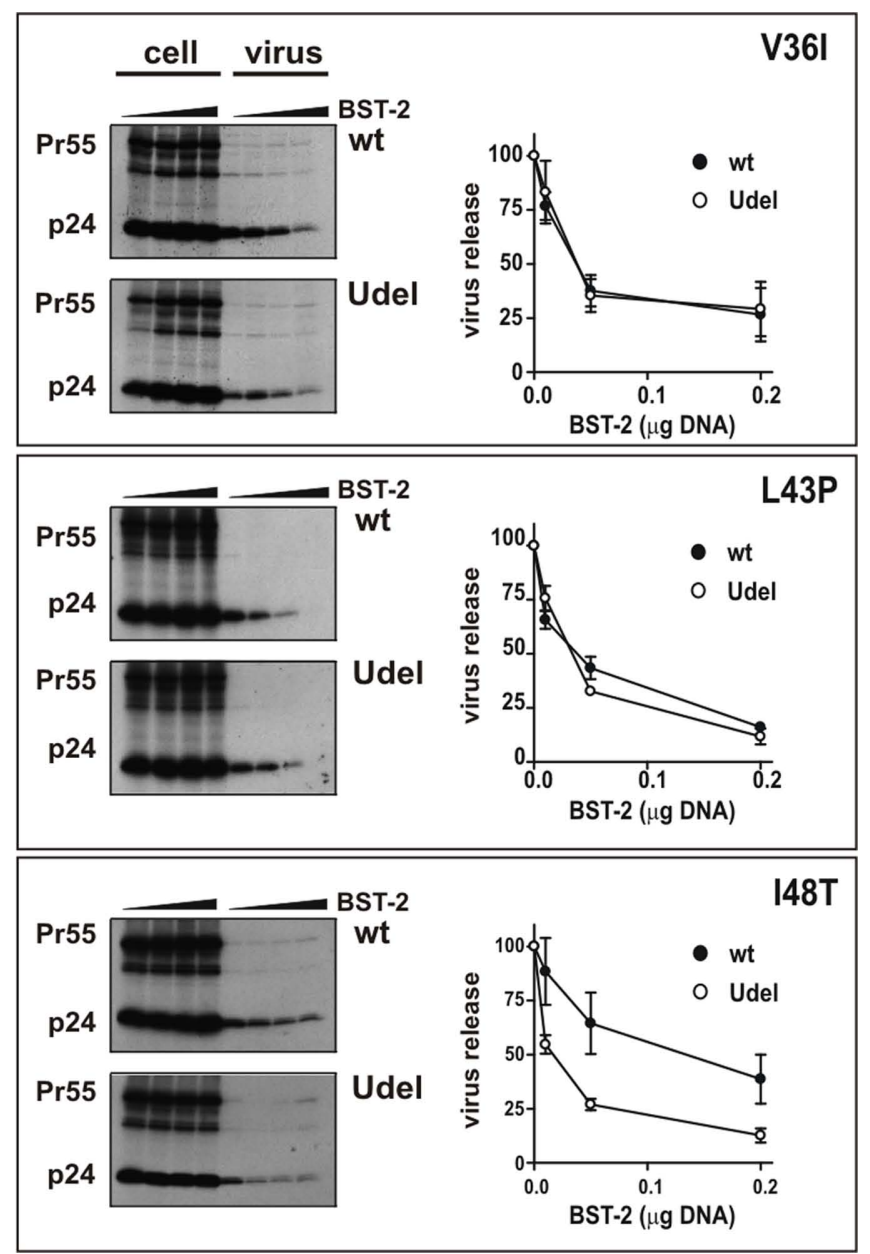

Representative fluorographs are shown. Quantitation of virus release is shown on the right of each panel and was performed as described in the legend to Figure 2B. Error bars reflect SEM from two independent experiments.

\section{ACKNOWLEDGMENTS}

We would like to thank Masashi Shingai for helpful discussion and for generously providing pooled rhesus macaque RNA for cloning of rhesus BST-2. We are grateful to Eri Miyagi, Amy Andrew, Robert C. Walker, Jr., and Sarah Welbourn for valuable suggestions and for critical comments on the manuscript. Thanks also to the members of the LMM core facility for sequence analysis and oligonucleotide synthesis. Pooled HIV-1 positive patient serum was obtained from the AIDS Research and Reference Reagent Program, Division of AIDS, NIAID, NIH: HIV-IG from NABI and NHLBI (Cat \# 3957). This work was supported in part by a Grant from the NIH Intramural AIDS Targeted Antiviral Program to Klaus Strebel and by the Intramural Research Program of the NIH, NIAID.

\section{REFERENCES}

Adachi, A., Gendelman, H. E., Koenig, S., Folks, T., Willey, R., Rabson, A., and Martin, M. A. (1986). Production of acquired immunodeficiency syndrome-associated retrovirus in human and nonhuman cells transfected with an infectious molecular clone. J. Virol. 59, 284-291.

Andrew, A., and Strebel, K. (2010). HIV-1 Vpu targets cell surface markers CD4 and BST-2 through distinct mechanisms. Mol. Aspects Med. 31, 407-417.

Andrew, A. J., Miyagi, E., Kao, S., and Strebel, K. (2009). The formation of cysteine-linked dimers of BST-2/ tetherin is important for inhibition of HIV-1 virus release but not for sensitivity to Vpu. Retrovirology 6, 80 .

Arnaud, F., Black, S. G., Murphy, L., Griffiths, D. J., Neil, S. J., Spencer, T. E., and Palmarini, M. (2010). Interplay between ovine bone marrow stromal cell antigen $2 /$ tetherin and endogenous retroviruses. J. Virol. 84, 4415-4425.

Bartee, E., McCormack, A., and Fruh, K. (2006). Quantitative membrane proteomics reveals new cellular targets of viral immune modulators. PLoS Pathog. 2, e107. doi: 10.1371/journal. ppat.0020107

Bour, S., Boulerice, F., and Wainberg, M.A. (1991). Inhibition of gp160 and CD4 maturation in U937 cells after both defective and productive infections by human immunodeficiency virus type 1. J. Virol. 65, 6387-6396.

Bour, S., Perrin, C., and Strebel, K. (1999). Cell surface CD4 inhibits HIV-1 particle release by interfering with Vpu activity. J. Biol. Chem. 274, 33800-33806.

Bour, S., Schubert, U., and Strebel, K. (1995). Thehuman immunodeficiency 
virus type $1 \mathrm{Vpu}$ protein specifically binds to the cytoplasmic domain of CD4: implications for the mechanism of degradation. J. Virol. 69, 1510-1520.

Buonocore, L., Turi, T. G., Crise, B., and Rose, J. K. (1994). Stimulation of heterologous protein degradation by the Vpu protein of HIV-1 requires the transmembrane and cytoplasmic domains of CD4. Virology 204, 482-486.

Crise, B., Buonocore, L., and Rose, J. K. (1990). CD4 is retained in the endoplasmic reticulum by the human immunodeficiency virus type 1 glycoprotein precursor. J. Virol. 64, 5585-5593.

Douglas, J. L., Viswanathan, K., McCarroll, M. N., Gustin, J. K., Fruh, K., and Moses, A. V. (2009). Vpu directs the degradation of the HIV restriction factor BST-2/tetherin via a \{beta\}TrCPdependent mechanism. J. Virol. 83, 7931-7947.

Dube, M., Roy, B. B., Guiot-Guillain, P., Binette, J., Mercier, J., Chiasson, A., and Cohen, E. A. (2010). Antagonism of tetherin restriction of HIV-1 release by $\mathrm{Vpu}$ involves binding and sequestration of the restriction factor in a perinuclear compartment. PLoS Pathog. 6, e1000856. doi: 10.1371/journal. ppat. 1000856

Dube, M., Roy, B. B., Guiot-Guillain, P., Mercier, J., Binette, J., Leung, G., and Cohen, E. A. (2009). Suppression of Tetherin-restricting activity upon human immunodeficiency virus type 1 particle release correlates with localization of $\mathrm{Vpu}$ in the trans-Golgi network. J. Virol. 83, 4574-4590.

Goffinet, C., Allespach, I., Homann, S., Tervo, H.M., Habermann, A., Rupp, D., Oberbremer, L., Kern, C., Tibroni, N., Welsch, S., Krijnse-Locker, J., Banting, G., Krausslich, H. G., Fackler, O. T., and Keppler, O. T. (2009). HIV-1 antagonism of CD317 is species specific and involves Vpu-mediated proteasomal degradation of the restriction factor. Cell Host Microbe 5, 285-297.

Goto, T., Kennel, S. J., Abe, M., Takishita, M., Kosaka, M., Solomon, A., and Saito, S. (1994). A novel membrane antigen selectively expressed on terminally differentiated human B cells. Blood 84, 1922-1930.

Gupta, R. K., Hue, S., Schaller, T., Verschoor, E., Pillay, D., and Towers, G. J. (2009). Mutation of a single residue renders human tetherin resistant to HIV-1 Vpu-mediated depletion. PLoS Pathog. 5, e1000443. doi: 10.1371/ journal.ppat.1000443

Habermann, A., Krijnse-Locker, J., Oberwinkler, H., Eckhardt, M., Homann, S., Andrew, A., Strebel, K., and Krausslich, H. G. (2010). CD317/ tetherin is enriched in the HIV-1 envelope and downregulated from the plasma membrane upon virus infection. J. Virol. 84, 4646-4658.

Hinz, A., Miguet, N., Natrajan, G., Usami, Y., Yamanaka, H., Renesto, P., Hartlieb, B., McCarthy, A. A., Simorre, J. P., Gottlinger, H., and Weissenhorn, W. (2010). Structural basis of HIV-1 tethering to membranes by the BST-2/ tetherin ectodomain. Cell Host Microbe 7, 314-323.

Hout, D. R., Gomez, M. L., Pacyniak, E., Gomez, L. M., Fegley, B., Mulcahy, E. R., Hill, M. S., Culley, N., Pinson, D. M., Nothnick, W., Powers, M. F., Wong, S. W., and Stephens, E. B. (2006). Substitution of the transmembrane domain of Vpu in simian-human immunodeficiency virus (SHIV(KU1bMC33)) with that of M2 of influenza A results in a virus that is sensitive to inhibitors of the M2 ion channel and is pathogenic for pig-tailed macaques. Virology 344, 541-559.

Hout, D. R., Gomez, M. L., Pacyniak, E., Gomez, L. M., Inbody, S. H., Mulcahy, E. R., Culley, N., Pinson, D. M., Powers, M. F., Wong, S. W., and Stephens, E. B. (2005). Scrambling of the amino acids within the transmembrane domain of Vpu results in a simian-human immunodeficiency virus (SHIV(TM)) that is less pathogenic for pig-tailed macaques. Virology 339, 56-69.

Ishikawa, J., Kaisho, T., Tomizawa, H., Lee, B. O., Kobune, Y., Inazawa, J., Oritani, K., Itoh, M., Ochi, T., Ishihara, K., and Hirano, T. (1995). Molecular cloning and chromosomal mapping of a bone marrow stromal cell surface gene, BST2, that may be involved in pre-Bcell growth. Genomics 26, 527-534.

Iwabu, Y., Fujita, H., Kinomoto, M., Kaneko, K., Ishizaka, Y., Tanaka, Y., Sata, T., and Tokunaga, K. (2009). HIV-1 accessory protein Vpu internalizes cell-surface BST-2/tetherin through transmembrane interactions leading to lysosomes. J. Biol. Chem. 284, 35060-35072.

Jabbar, M. A., and Nayak, D. P. (1990). Intracellular interaction of human immunodeficiency virus type 1 (ARV-2) envelope glycoprotein gp160 with CD4 blocks the movement and maturation of CD4 to the plasma membrane. J. Virol. 64, 6297-6304.

Jia, B., Serra-Moreno, R., Neidermyer, W., Rahmberg, A., Mackey, J., Fofana, I. B., Johnson, W.E., Westmoreland, S., and Evans, D. T. (2009). Species-specific activity of SIV Nef and HIV-1 Vpu in overcoming restriction by tetherin/ BST2. PLoS Pathog. 5, e1000429. doi: 10.1371/journal.ppat.1000429
Jouvenet, N., Neil, S. J., Zhadina, M., Zang, T., Kratovac, Z., Lee, Y., McNatt, M., Hatziioannou, T., and Bieniasz, P. D. (2009). Broad-spectrum inhibition of retroviral and filoviral particle release by tetherin. J. Virol. 83, 1837-1844.

Kaletsky, R. L., Francica, J. R., AgrawalGamse, C., and Bates, P. (2009). Tetherin-mediated restriction of filovirus budding is antagonized by the Ebola glycoprotein. Proc. Natl. Acad. Sci. U.S.A. 106, 2886-2891.

Klimkait, T., Strebel, K., Hoggan, M. D., Martin, M. A., and Orenstein, J. M. (1990). The human immunodeficiency virus type 1-specific protein $\mathrm{vpu}$ is required for efficient virus maturation and release. J. Virol. 64, 621-629.

Kobayashi, T., Ode, H., Yoshida, T., Sato, K., Gee, P., Yamamoto, S. P., Ebina, H., Strebel, K., Sato, H., and Koyanagi, Y. (2011). Identification of amino acids in the human tetherin transmembrane domain responsible for HIV-1 Vpu interaction and susceptibility. J. Virol. 85, 932-945.

Kupzig, S., Korolchuk, V., Rollason, R., Sugden, A., Wilde, A., and Banting, G. (2003). Bst-2/HM1.24 is a raftassociated apical membrane protein with an unusual topology. Traffic 4 694-709.

Magadan, J. G., Perez-Victoria, F. J., Sougrat, R., Ye, Y., Strebel, K., and Bonifacino, J. S. (2010). Multilayered mechanism of CD4 downregulation by HIV-1 Vpu involving distinct ER retention and ERAD targeting steps. PLoS Pathog. 6, e1000869. doi: 10.1371/journal.ppat.1000869

Maldarelli, F., Chen, M. Y., Willey, R. L., and Strebel, K. (1993). Human immunodeficiency virus type $1 \mathrm{Vpu}$ protein is an oligomeric type I integral membrane protein. J. Virol. 67, 5056-5061.

Masuyama, N., Kuronita, T., Tanaka, R., Muto, T., Hirota, Y., Takigawa, A., Fujita, H., Aso, Y., Amano, J., and Tanaka, Y. (2009). HM1.24 is internalized from lipid rafts by clathrin-mediated endocytosis through interaction with \{alpha\}-adaptin. J. Biol. Chem. 284, 15927-15941.

Mattiuzzo, G., Ivol, S., and Takeuchi, Y. (2010). Regulation of porcine endogenous retrovirus release by porcine and human tetherins. J. Virol. 84 2618-2622.

McNatt, M. W., Zang, T., Hatziioannou, T., Bartlett, M., Fofana, I. B., Johnson, W. E., Neil, S. J., and Bieniasz, P. D. (2009). Species-specific activity of HIV-1 Vpu and positive selection of tetherin transmembrane domain variants. PLoS Pathog. 5, e1000300. doi: 10.1371/journal.ppat.1000300
Mitchell, R. S., Katsura, C., Skasko, M. A., Fitzpatrick, K., Lau, D., Ruiz, A., Stephens, E. B., Margottin-Goguet, F., Benarous, R., and Guatelli, J.C. (2009). Vpu antagonizes BST-2-mediated restriction of HIV-1 release via betaTrCP and endo-lysosomal trafficking. PLoS Pathog. 5, e1000450. doi: 10.1371/journal.ppat. 1000450

Miyagi, E., Andrew, A. J., Kao, S., and Strebel, K. (2009). Vpu enhances HIV-1 virus release in the absence of Bst-2 cell surface down-modulation and intracellular depletion. Proc. Natl. Acad. Sci. U.S.A. 106 2868-2873.

Neil, S. J., Eastman, S. W., Jouvenet, N. and Bieniasz, P. D. (2006). HIV-1 Vpu promotes release and prevents endocytosis of nascent retrovirus particles from the plasma membrane. PLoS Pathog. 2, e39. doi: 10.1371/journal. ppat.0020039

Neil, S. J., Sandrin, V., Sundquist, W. I., and Bieniasz, P. D. (2007). An interferonalpha-induced tethering mechanism inhibits HIV-1 and Ebola virus particle release but is counteracted by the HIV-1 Vpu protein. Cell Host Microbe 2, 193-203.

Neil, S. J., Zang, T., and Bieniasz, P. D. (2008). Tetherin inhibits retrovirus release and is antagonized by HIV-1 Vpu. Nature 451, 425-430.

Nguyen, K. L., llano, M., Akari, H., Miyagi, E., Poeschla, E. M., Strebel, K., and Bour, S. (2004). Codon optimization of the HIV-1 vpu and vif genes stabilizes their mRNA and allows for highly efficient Rev-independent expression. Virology 319, 163-175.

Ohtomo, T., Sugamata, Y., Ozaki, Y. Ono, K., Yoshimura, Y., Kawai, S., Koishihara, Y., Ozaki, S., Kosaka, M., Hirano, T., and Tsuchiya, M. (1999). Molecular cloning and characterization of a surface antigen preferentially overexpressed on multiple myeloma cells. Biochem. Biophys. Res. Commun. 258, 583-591.

Paul, M., Mazumder, S., Raja, N., and Jabbar, M. A. (1998). Mutational analysis of the human immunodeficiency virus type $1 \mathrm{Vpu}$ transmembrane domain that promotes the enhanced release of virus-like particles from the plasma membrane of mammalian cells. J. Virol. 72, 1270-1279.

Perez-Caballero, D., Zang, T., Ebrahimi, A., McNatt, M. W., Gregory, D. A., Johnson, M. C., and Bieniasz, P. D. (2009). Tetherin inhibits HIV-1 release by directly tethering virions to cells. Cell 139, 499-511.

Raja, N. U., Vincent, M. J., and Jabbar, M. A. (1994). Vpu-mediated proteolysis of gp160/CD4 chimeric envelope glycoproteins in the endoplasmic 
reticulum: requirement of both the anchor and cytoplasmic domains of CD4. Virology 204, 357-366.

Rollason, R., Korolchuk, V., Hamilton, C., Schu, P., and Banting, G. (2007). Clathrin-mediated endocytosis of a lipid-raft-associated protein is mediated through a dual tyrosine motif. J. Cell Sci. 120, 3850-3858.

Rong, L., Zhang, J., Lu, J., Pan, Q., Lorgeoux, R. P., Aloysius, C., Guo, F., Liu, S. L., Wainberg, M. A., and Liang, C. (2009). The transmembrane domain of BST-2 determines its sensitivity to down-modulation by HIV-1 Vpu. J. Virol. 83, 7536-7546.

Sakai, H., Tokunaga, K., Kawamura, M., and Adachi, A. (1995). Function of human immunodeficiency virus type $1 \mathrm{Vpu}$ protein in various cell types. $J$. Gen. Virol. 76(Pt 11), 2717-2722.

Sakuma, T., Noda, T., Urata, S., Kawaoka, Y., and Yasuda, J. (2009a). Inhibition of Lassa and Marburg virus production by tetherin. J. Virol. 83, 2382-2385.

Sakuma, T., Sakurai, A., and Yasuda, J. (2009b). Dimerization of tetherin is not essential for its antiviral activity against Lassa and Marburg viruses. PLoS ONE 4, e6934. doi: 10.1371/journal.pone.0006934
Schubert, U., Bour, S., Ferrer-Montiel, A. V., Montal, M., Maldarell, F., and Strebel, K. (1996). The two biological activities of human immunodeficiency virus type $1 \mathrm{Vpu}$ protein involve two separable structural domains. J. Virol. 70, 809-819.

Strebel, K. (2007). HIV accessory genes Vif and Vpu. Adv. Pharmacol. 55, 199-232.

Strebel, K., Beck, E., Strohmaier, K., and Schaller, H. (1986). Characterization of foot and mouth disease virus gene products with antisera against bacterially synthesized fusion proteins. $J$. Virol. 57, 983-991.

Strebel, K., Klimkait, T., and Martin, M. A. (1988). A novel gene of HIV-1, vpu, and its 16-kilodalton product. Science 241, 1221-1223.

Terwilliger, E. F., Cohen, E. A., Lu, Y. C., Sodroski, J. G., and Haseltine, W. A. (1989). Functional role of human immunodeficiency virus type 1 vpu. Proc. Natl. Acad. Sci. U.S.A. 86, 5163-5167.

Tiganos, E., Yao, X. J., Froborg, J., Daniel, N., and Cohen, E. A. (1997). Putative a-helical structures in the human immunodeficiency virus type $1 \mathrm{Vpu}$ protein and CD4 are involved in binding and degradation of the CD4 molecule. J. Virol. 71, 4452-4460.
Van Damme, N., Goff, D., Katsura, C. Jorgenson, R. L., Mitchell, R., Johnson, M. C., Stephens, E. B., and Guatelli, J. (2008). The interferon-induced protein BST-2 restricts HIV-1 release and is downregulated from the cell surface by the viral Vpu protein. Cell Host Microbe 3, 245-252.

Varthakavi, V., Smith, R. M., Bour, S. P., Strebel, K., and Spearman, P. (2003). Viral protein U counteracts a human host cell restriction that inhibits HIV-1 particle production. Proc. Natl. Acad. Sci. U.S.A. 100, 15154-15159.

Varthakavi, V., Smith, R. M., Martin, K. L., Derdowski, A., Lapierre, L. A., Goldenring, J. R., and Spearman, P. (2006). The pericentriolar recycling endosome plays a key role in $\mathrm{Vpu}$ mediated enhancement of HIV-1 particle release. Traffic 7, 298-307.

Willey, R. L., Buckler-White, A., and Strebel, K. (1994). Sequences present in the cytoplasmic domain of CD4 are necessary and sufficient to confer sensitivity to the human immunodeficiency virus type $1 \mathrm{Vpu}$ protein. J. Virol. 68, 1207-1212.

Yao, X. J., Friborg, J., Checroune, F., Gratton, S., Boisvert, F., Sekaly, R. P., and Cohen, E. A. (1995). Degradation of CD4 induced by human immunodeficiency virus type 1 Vpu protein: a predicted alpha-helix structure in the proximal cytoplasmic region of CD4 contributes to Vpu sensitivity. Virology 209, 615-623.

Conflict of Interest Statement: The authors declare that the research was conducted in the absence of any commercial or financial relationships that could be construed as a potential conflict of interest.

Received: 09 November 2010; accepted: 09 February 2011; published online: 18 February 2011.

Citation: Yoshida T, Kao S and Strebel K (2011) Identification of residues in the BST-2 TM domain important for antagonism by HIV-1 Vpu using a gain-offunction approach. Front. Microbio. 2:35. doi: 10.3389/fmicb.2011.00035

This article was submitted to Frontiers in Virology, a specialty of Frontiers in Microbiology.

Copyright (c) 2011 Yoshida, Kao and Strebel. This is an open-access article subject to an exclusive license agreement between the authors and Frontiers Media $S A$, which permits unrestricted use, distribution, and reproduction in any medium, provided the original authors and source are credited. 